\title{
Impact of the duct static pressure reset control strategy on the energy consumption by the HVAC system
}

\author{
Juliusz Walaszczyk ${ }^{1, *}$, and Aleksandra Cichoń $^{1}$ \\ ${ }^{1}$ Wroclaw University of Science and Technology, Faculty of Environmental Engineering, Wybrzeze \\ S. Wyspianskiego 27, Wrocław, Poland
}

\begin{abstract}
This article addresses different duct static pressure control strategies which could be implemented in variable air volume airconditioning systems (VAV). Two pressure reset control strategies are compared to the commonly used control solution based on the "Constant static pressure" method. First pressure reset control strategy, known as PID Control, uses signals from VAV boxes controllers to reset duct static pressure in a way that one of the VAV dampers is maintained almost entirely open. Second strategy decreases static pressure setpoint until an adjustable number of pressure requests occur. As a response to the certain amount of requests, static pressure setpoint is increased. This strategy is called Trim \& Respond. Both static pressure reset control strategies described in this paper are considered to have more significant potential for energy savings than the "Constant static pressure" method. In order to validate this potential, several simulations for different control strategies were carried out and the obtained results are compared and analysed. The theoretical limit of the energy savings - set of the optimal control actions, was estimated with Nelder-Mead algorithm and also presented in this article. General description of the static pressure control strategies "Constant static pressure", PID Control and Trim \& Respond is given.
\end{abstract}

\section{Introduction}

Variable air volume systems have been applied since the end of the World War II [1], while the term VAV (variable air volume), was formulated and first used almost two decades later in the sixties of the last century [2]. VAV systems became widely popular in the middle of the seventies, as a result of the 1970 energy and oil crisis. In continental Europe, VAVs gained their popularity in the eighties. Currently they are commonly applied and implemented in the modern HVAC installations.

A typical VAV system consists of variable air volume zone boxes with dampers and variable speed fans. In response to varying loads in the ventilating zones, VAV damper's position changes in order to maintain required airflow. The changing damper's position affects on a static pressure value in a duct system. As static pressure changes,

*Corresponding author: juliusz.walaszczyk@pwr.edu.pl 
a fan responds by adjusting its speed to the point which allows to maintain static pressure at a given setpoint. For example, when zone's load decreases, less air volume is required and the zone's damper closes. At the same time fan reduces its speed to maintain constant duct static pressure. Lowered fan speed results in reduced total energy consumption. "Constant static pressure" control strategy is an efficient solution for energy savings but it is considered that the static pressure reset strategy is much more effective [3, 4].

In order to investigate the impact of the duct static pressure reset control strategy on the energy consumption by HVAC system, PID Control and Trim \& Respond strategies were described and compared to the "Constant static pressure" method. In order to present the energy savings limit and potential for future research, optimal control actions was investigated. Optimal control actions were estimated using Nelder-Mead algorithm and then used as a benchmark for other presented strategies (Fig. 1).

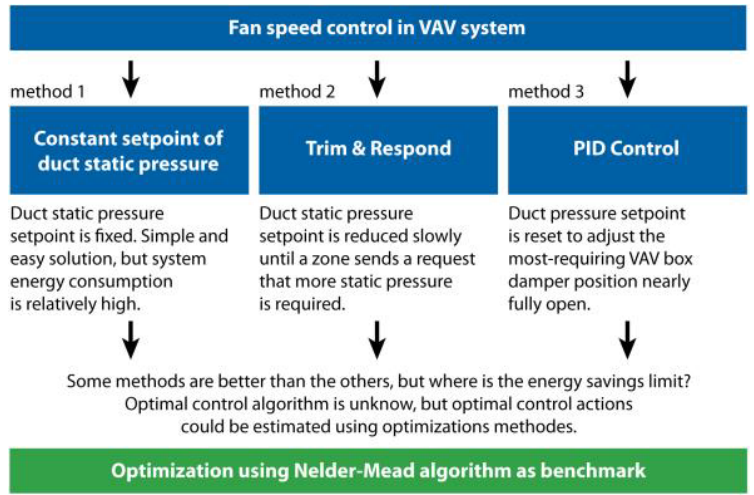

Fig.1. Graphical presentation of the research methodology.

\section{Duct Static Pressure Reset Control Strategies}

Since 1999, ASHRAE Standard 90.1 has required that static pressure setpoint should be reset for each system with direct digital control (DDC) at the zone level, instead of maintaining constant value of the duct static pressure. Static pressure reset control strategies saved fan energy and at the same time all zone's demands are met and required amount of air is supplied [5]. It is considered that the demand-based static pressure setpoint reset has potential to save fan energy up to $50 \%$, compared with maintaining the constant pressure setpoint [6]. In the next two subsections, the most popular pressure reset control strategies PID Control and Trim \& Respond are described.

\subsection{PID Control}

PID Control and its simpler set, the PI control, have been used to regulate a wide range of individual devices in complex HVAC systems. In the past few decades with increasing use of Direct Digital Control (DDC) units, PI and PID Control methods have been widely implemented in the pressure reset control strategies [5]. PID Control approach involves a standard proportional-integral-derivate (PID) control loop to determine the static pressure setpoint. Under this strategy, as the zone's demand decreases and the zone's damper begin to close, the duct static pressure setpoint is reduced until the most requiring VAV box damper is nearly wide open (it is recommended to not use the $100 \%$ value, because the PID loop requires the error margin on both sides of the setpoint [7]). In the recent studies, PID 
Control method is pointed out as a simple way for energy savings, but is not recommended while the other method, Trim \& Respond is available [6].

\subsection{Trim \& Respond}

With Trim and Respond (T\&R) approach, the duct static pressure setpoint is reduced slowly until any zone sends a request that more static pressure is required. As a response to the certain amount of pressure requests, system controller increases the pressure setpoint. The importance of each zone's request could be adjusted in order to ensure that the critical zone's demand is always satisfied. On the other hand, the T\&R method allows identifying the zones that are too demanding (rogue zones) so that they could be ignored and excluded from the control loop. In many research, $T \& R$ method has been found to be the most effective approach to reduce energy costs. The main advantage of $T \& R$ method over the PID Control strategy is that the T\&R method does not require knowledge about damper position, while PID logic does.

The important advantage of the T\&R control strategy is that it is easier to deal with rogue zones. A rogue zone could occur in any VAV system for a number of different reasons hence the "rogue zone" definition is not unified as well. In general, a rogue zone is defined as a VAV box that generates the disproportionately large amount of requests over time. Static pressure reset strategy is a demand-based sequence so that it works properly only if there is a good agreement between installation sizing and actual loads. If any VAV box is undersized, a damper position would be constantly open and send requests to increase static pressure. In this case, while most of the other damper positions are around $40 \%$ open, this zone may be identified as a rogue zone and therefore no reliable static pressure reset is possible. One of the possible solutions to deal with the rogue zone is to omit it in the control loop. A recent version of ASHRAE Standard from 2013 has required that DDC system control logic should allow to identify rogue zone and the operator should be able to exclude this zone from the control algorithm. With the T\&R logic, it is relatively easy to ignore one or more rogue zones with adjusting a certain number of pressure requests that must be received before the pressure is increased. It is much more difficult to do it with the standard PID logic so that the T\&R method is more recommended [8].

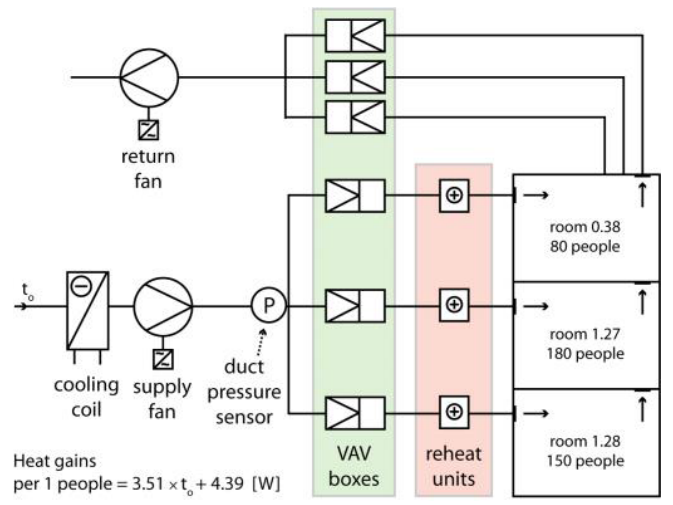

Fig. 2. Diagram of the modelled VAV system.

\section{Model and simulations}

In this article different pressure control strategies were compared based on the simulation results. The simulation of 1 hour period was carried out for different outdoor 
temperatures from range $13-19^{\circ} \mathrm{C}$ with $0,5^{\circ} \mathrm{C}$ step. Constant heat gains at given outdoor temperature were assumed. In this simulation heat gains depend only on the number of people in the room and change linearly in the function of the external temperature. Schematic diagram of the modelled installation is presented on the Fig. 2.

\subsection{Total energy demand}

All pressure control algorithms presented in this article, were compared on the basis of the total energy demand calculated over the period of 1 hour. "Constant static pressure", PID Control, and optimal control actions were investigated under the system's steady state. As the steady state is once established it is possible to calculate the total energy consumption directly from the power demand (Eq. (1)).

$$
E=P \cdot t
$$

where: $E$ - total energy demand [Wh], $P$ - steady state power demand [W], $t$ - time [h].

Total power demand is the sum of the power demands of each part of the VAV system. Fan power $\mathrm{P}_{\mathrm{F}}$ is calculated using Eq. (2).

$$
P_{F}=\Delta p \cdot V / \eta
$$

where: $\Delta p$ - fan pressure [Pa], $V$ - volumetric airflow $\left[\mathrm{m}^{3} / \mathrm{s}\right], \eta$ - fan efficiency.

Thermal power of each air treatment process in the air-conditioning unit is calculated using Eq. (3).

$$
P_{\text {term }}=V \cdot \rho \cdot c_{v} \cdot \Delta T / \eta_{\text {term }}
$$

where: $\rho$ - air density $\left[\mathrm{kg} / \mathrm{m}^{3}\right], c_{v}$ - specific heat $[\mathrm{J} /(\mathrm{kg} \cdot \mathrm{K})], \Delta T$ - temperature difference at the inlet and outlet of the thermal unit $[\mathrm{K}], \eta_{\text {term }}$ - normalized thermal power coefficient.

Thermal power in the air treatment process is calculated using the coefficient $\eta_{\text {term }}$ (Eq. (4)). The coefficient value is estimated with the thermal energy cost and the cost of equivalent electric energy. Normalization was made in order to compare an electric and thermal energy at the same basis.

$$
\eta_{\text {term }}=\text { electric energy cost / thermal energy cost }
$$

\subsection{Constant static pressure simulation}

"Constant static pressure" strategy maintains the constant value of the static pressure in the point of the installation, where the main duct divides into the individual VAV branches (see Fig. 2). Static pressure is set at the level that provides the designed airflow at nominal heat gains. In this strategy fan speed is adjusted to maintain constant static pressure level $\left(\mathrm{P}_{\max }=534,5 \mathrm{~Pa}\right)$ under every operational conditions.

\subsection{PID Control simulation}

PID Control simulation was carried out with the assumption that at least one of the VAV dampers was almost open. The air resistance factor S (Eq. (5)) [9] was determined for every branch in the VAV system (with damper fully open). Every increase in the $\mathrm{S}$ indicates that the VAV damper closes. To described the situation when the damper is "almost" entirely open, S (determined while damper fully open), should not increase more than 4. 


$$
S=\Delta p_{n} / w_{n}^{2}
$$

where: $S$ - air resistance factor, $\Delta p_{n}$ - pressure drop over duct branch [Pa], $w_{n}$ - airflow speed in $n$ branch $[\mathrm{m} / \mathrm{s}]$.

\subsection{Trim \& Respond simulation}

The static pressure setpoint under $T \& R$ algorithm is determined as a response for requests from the zone level. In this research, requests are established into different thresholds. While the difference between the set and the measured value of the single VAV airflow volume is less than $0,02 \mathrm{~m}^{3} / \mathrm{s}$, then the first type of request is generated. While the same difference is less than $0,1 \mathrm{~m}^{3} / \mathrm{s}$, the request of the second type is send. As a result of this approach, every second type request forces the first type request to generate as well, so that two requests may be send from the single zone. This strategy results in increasing system flexibility, so that every zone's demand is met, even if only a single zone requires higher static pressure.

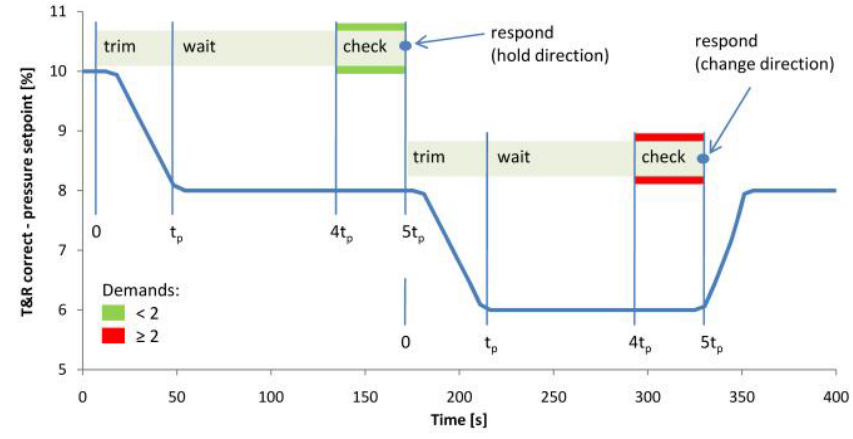

Fig. 3. Pressure setpoint value as a maximum static pressure percentage, indicates by the $T \& R$ algorithm over time.

The T\&R strategy implemented into simulation proceeds in a following order (Fig. 3): Step 1: Started at 0 until $t_{p}$, pressure setpoint value is reset downwards by $2 \%$ (where $0 \%$ is $\mathrm{P}_{\min }=133.4 \mathrm{~Pa}$ and $100 \%$ is $\mathrm{P}_{\max }=534.5 \mathrm{~Pa}$ ). Step 2: Pressure setpoint reset causes decrease in fan speed (due to fan speed control loop) and hence VAV boxes become more open (due to VAV dampers control loops). These events take time, therefore from time $t_{p}$ to $4 t_{p}$, control algorithm stands by, because all control loops should stabilize. Step 3: From time $4 t_{p}$ to $5 t_{p}$, control algorithm receives the requests from the zones. Step 4: At the time $5 t_{p}$, control algorithm decides whether to increase or keep decreasing the pressure setpoint. The decision depends on the number of request received from the VAV boxes. In this study, the number of 2 requests was set as a limiting value.

While the T\&R method is characterized by the varying pressure setpoint, fan pressure and fan power varies as well. In case of the non-steady state, the Eq. (1) cannot be used to calculate total energy demand. In case of T\&R strategy, instantaneous power demand must be integrated with respect to time.

\subsection{Optimal control simulation}

It is possible to identify a set of the control actions for which a HVAC system consumes minimum energy. This set of optimal control actions could be delivered from the NelderMead simplex optimization method. In this research the optimization process was carried out multiply for different start points. The optimization results were used as a benchmark 
for "Constant static pressure" and pressure reset control strategies: PID Control and T\&R. Matlab built-in Nelder-Mead simplex method, implemented in the function fminsearch, was used. Optimization was made on the function $\mathrm{P}_{\text {HVAC }}$ (Eq. (6)).

$$
P_{H V A C}\left(\Delta p_{S D} ; \Delta p_{R D} ; t_{o} ; V_{1} ; V_{2} ; V_{3}\right)=P_{\text {term CC }}+P_{\text {termR } 1}+P_{\text {termR } 2}+P_{\text {termR } 3}+P_{S F}+P_{R F}
$$

where: $P_{H V A C}$ - total system power [W], $\Delta p_{S D}\left(\Delta p_{R D}\right)$ - supply (return) duct static pressure $[\mathrm{Pa}], t_{o}$ - outdoor air temperature $\left[{ }^{\circ} \mathrm{C}\right], V_{l}\left(V_{2}, V_{3}\right)$ - supply airflow to the room 0.38 (1.27, $1.28)\left[\mathrm{m}^{3} / \mathrm{s}\right], P_{\text {termCC }}-$ cooling power $[\mathrm{W}], P_{\text {termRI }}\left(P_{\text {termR } 2}, P_{\text {termR } 3}\right)-$ reheat power for room $0.38(1.27,1.28)[\mathrm{W}], P_{S F}\left(P_{R F}\right)-$ supply (return) fan power [W].

\section{Results}

In this section, the results of the conducted simulations are presented. On the Fig. 4 and 5, fan power under "Constant static pressure", PID Control, T\&R and optimal control actions is presented with regard to the static pressure setpoint signal in the T\&R algorithm. The graph on Fig. 4 presents the simulation results in $13^{\circ} \mathrm{C}$ outdoor temperature, and graph on Fig. 5 in $16^{\circ} \mathrm{C}$.

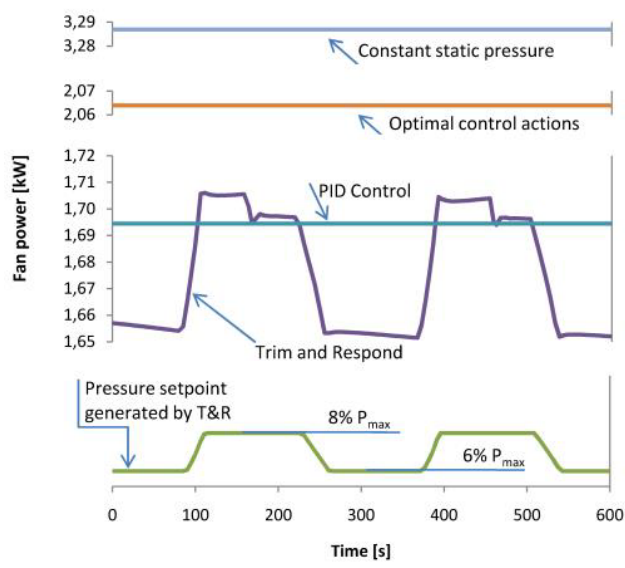

Fig. 4. The simulation results of the fan power for $13^{\circ} \mathrm{C}$ outdoor temperature.

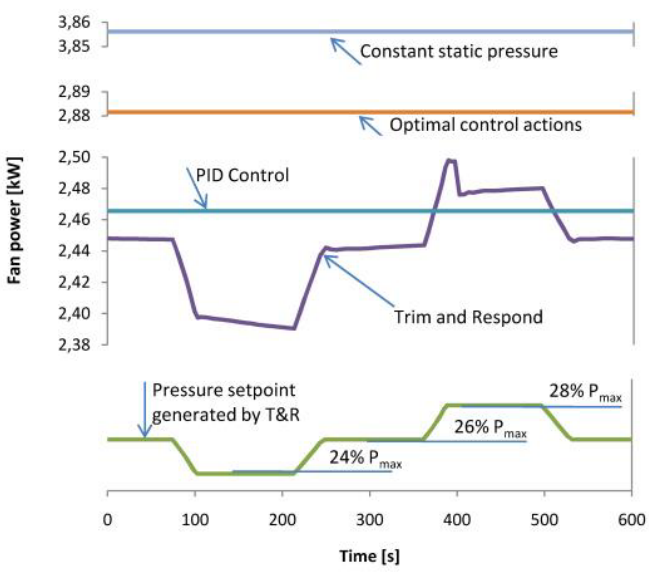

Fig. 5. The simulation results of the fan power for $16^{\circ} \mathrm{C}$ outdoor temperature. 
Besides T\&R, all analyzed methods are characterized by the constant fan power. This results from the system's steady state. Under T\&R fan power changes periodically. While the pressure setpoint increases (in other word a required amount of requests occurs), the fan speed controller reacts and hence the fan power increases (under-regulations are registered). If there are no further requests from the zones' VAV boxes, T\&R strategy starts to decrease the static pressure setpoint. As in the case of $13^{\circ} \mathrm{C}$ outdoor temperature, the $\mathrm{T} \& \mathrm{R}$ control loop proceeds in one step (single pressure setpoint increase of $2 \%$ ) or in the two or more steps sequence like in the case of $16^{\circ} \mathrm{C}$ outdoor temperature (two pressure setpoint increase of $4 \%$ summarily).

The highest fan power demand is noticed for the "Constant static pressure" method. Fan power under PID Control was found to be almost 50\% less than the one under constant static pressure regulation. Optimal control actions results in decreasing fan power demand while comparing to the "Constant static pressure". At the same time, fan power demand under optimal control actions is higher than under PID Control and T\&R method, which seems to contradict with the word "optimal" itself. Under these control actions, the "optimal" effect is achieved by the fact that these actions employ not only pressure control strategy, but temperature control strategy as well. In this case, whenever possible, heat gains from the zones are removed by increased airflow volume rather than increasing cooling power. Thus, the supply airflow temperature required to meet zones demands, could be higher than under other pressure control strategies, and so the cooling energy consumption decreases. At the same time, increased airflow volume increases the fan power demand, which could be observed on the Fig. 6 .

Any difference in fan power demand results not only from the different airflow volume, but also from the pressure loss on the VAV boxes dampers. Basically, the airflow volume setpoint for a specific outdoor temperature is identical in every analyzed control methods (under T\&R method, the airflow volume fluctuates periodically around the constant setpoint). This does not concern the optimal control algorithm, under which the airflow volume is set based on overall (fan and air treatment) energy demand. In case of the same airflow volume under "Constant static pressure", PID Control and T\&R method, any difference in fan power derives from different damper's position. While dampers are more open, pressure loss is low and hence less energy is needed to transport required amount of the air. Under the PID Control and T\&R method, at least one damper is always almost open, which results in lower pressure loss in the duct system in comparison with "Constant static pressure" method.

\section{Analysis and conclusions}

In this article three possible static pressure control strategies were described and compared with regard to the energy consumption. "Constant static pressure", PID Control and Trim \& Respond control strategy were investigated and referenced to the optimal control actions. Optimal control actions were used to present a hypothetical limit of the energy savings.

On the Fig. 6, total energy consumption, which is the sum of the energy consumption by thermal treatment and fan energy (on the left) and fan energy consumption alone (on the right), for different pressure control strategies, is presented. The highest total and fan energy consumption is noticed for the "Constant static pressure" method. While total energy consumption is taken into consideration, pressure reset control methods (PID Control and Trim \& Respond) have a potential to reduce energy consumption from 5 (for $19^{\circ} \mathrm{C}$ ) to $26 \%$ (for $13^{\circ} \mathrm{C}$ ) compared to the "Constant static pressure" method. Furthermore, fan energy consumption under pressure reset control methods was found to be from 22 (for $19^{\circ} \mathrm{C}$ ) up to $48 \%$ (for $13^{\circ} \mathrm{C}$ ) lower. 


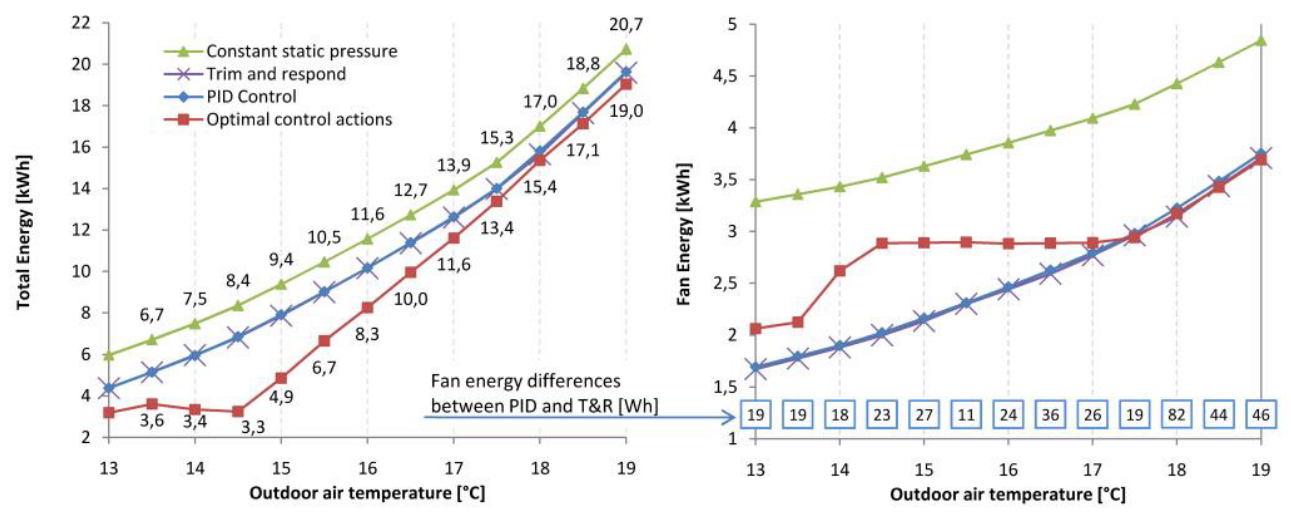

Fig. 6. Total energy consumption (on the left) and fan energy consumption (on the right) for different pressure control strategies.

Energy consumption in the thermal air treatment process is the same under PID Control, T\&R and "Constant static pressure". This results from the fact that the parameters of supply air depend only on the current demand. The pressure control strategies different from each other only in the matter of approach in decreasing pressure setpoint and, in the final effect, fan energy consumption.

In case of the pressure reset control strategies (PID Control and T\&R), the abovementioned differences are minimal as it could be seen on the Fig. 6. Total energy consumption, which is the sum of the fan and thermal air treatment energy consumption, shows no significant differences under PID Control and T\&R control strategy.

The slightly higher fan energy consumption under PID Control method compared with the T\&R strategy is noted for every outdoor temperature. However, these differences were found to increase with an increasing outdoor temperature. This could results from the fact that in the PID Control strategy, VAV damper position is not fully open. This additional minor air resistance on the VAV damper has the major effect on the pressure loss. It is caused by the fact that pressure loss increases with increasing airflow volume (pressure loss rises with the squared airflow speed). Under the T\&R control strategy, at least one VAV damper is periodically fully open for a while, so that the fan energy consumption is lower than under PID Control (Fig. 4 and 5). At the same time, this could lead to a situation when airflow is lower than required setpoint, which is the main disadvantage of the T\&R method. In conclusion, total and fan energy consumption under PID Control and T\&R strategy are similar, but with minor advantage of the T\&R method. Energy consumption is reduced but at the expense of meeting zones' demand.

Above all, it is clearly noticeable that pressure reset control methods (PID Control and Trim \& Respond) have a great potential to reduce energy consumption compared with the "Constant static pressure" control method. Since it is not possible to reduced static pressure setpoint under a certain critical value, it is assumed that no further energy savings are possible while using PID Control or T\&R control strategy. However, the optimization process showed a promising potential in reducing energy consumption. At the outdoor temperature range from 13 to $17^{\circ} \mathrm{C}$, airflow volume under optimal control actions is relatively high, so that the fan energy consumption increases (Fig. 6 on the right). At the same time, this approach allows to lower the cooling/reheating demand, so that the increased air volume is able to meet the zones' requirements without additional energy consumption in the thermal air treatment process. This issue could be also addressed otherwise. While supply air temperature increases, cooling/reheating energy consumption 
decreases and fan energy consumption rises at the same time. Supply air temperature optimization process is usually called Supply Air Temperature (SAT) reset and could be investigated in the future researches.

\section{References}

1. A. Pełech, Wentylacja i klimatyzacja - podstawy (2008)

2. G.S. Okochi, Y. Yao, A review of recent developments and technological advancements of variable-air-volume (vav) air-conditioning systems, Renewable and Sustainable Energy Reviews, 59 (2016)

3. R.W. Haines, Control Systems for Heating, Ventilating and Air Conditioning, Van Nostrand Company, E 4 (1987)

4. H. Recknagel, E.-R. Schramek, Kompendium Ogrzewnictwa i Klimatyzacji (2008)

5. B.W. Householder, A study on static pressure reset and instability in variable air volume HVAC systems (2011), Graduate Theses and Dissertations

6. Energy Design Resources, The advanced variable air volume (VAV) system design guide (2009)

7. S.T. Taylor, Resetting Setpoints Using Trim \& Respond Logic, ASHRAE JOURNAL, November (2015)

8. T. Hartman, Terminal regulated air volume (trav) systems, 99 (1993)

9. G. Liu, M. Liu, Supply Fan Control Methods for VAV Systems Using a Fan Airflow Station, ASHRAE Transactions NY-08-055 (2008) 